\title{
Influence of CYP3A5 Genetic Polymorphism on Long- Term Renal Function in Chinese Kidney Transplant Recipients Using Limited Sampling Strategy and Abbreviated Area Under the Curve for Tacrolimus Monitoring
}

Citation for published version (APA):

Cheung, C. Y., Chan, K. M., Wong, Y. T., Chak, W. L., Bekers, O., \& van Hooff, J. P. (2020). Influence of CYP3A5 Genetic Polymorphism on Long-Term Renal Function in Chinese Kidney Transplant Recipients Using Limited Sampling Strategy and Abbreviated Area Under the Curve for Tacrolimus Monitoring. Progress in Transplantation, 30(3), 249-253. [1526924820933823]. https://doi.org/10.1177/1526924820933823

Document status and date:

Published: 01/09/2020

DOI:

$10.1177 / 1526924820933823$

Document Version:

Publisher's PDF, also known as Version of record

\section{Document license:}

Taverne

Please check the document version of this publication:

- A submitted manuscript is the version of the article upon submission and before peer-review. There can be important differences between the submitted version and the official published version of record. People interested in the research are advised to contact the author for the final version of the publication, or visit the DOI to the publisher's website.

- The final author version and the galley proof are versions of the publication after peer review.

- The final published version features the final layout of the paper including the volume, issue and page numbers.

Link to publication

\footnotetext{
General rights rights.

- You may freely distribute the URL identifying the publication in the public portal. please follow below link for the End User Agreement:

www.umlib.nl/taverne-license

Take down policy

If you believe that this document breaches copyright please contact us at:

repository@maastrichtuniversity.nl

providing details and we will investigate your claim.
}

Copyright and moral rights for the publications made accessible in the public portal are retained by the authors and/or other copyright owners and it is a condition of accessing publications that users recognise and abide by the legal requirements associated with these

- Users may download and print one copy of any publication from the public portal for the purpose of private study or research.

- You may not further distribute the material or use it for any profit-making activity or commercial gain

If the publication is distributed under the terms of Article $25 \mathrm{fa}$ of the Dutch Copyright Act, indicated by the "Taverne" license above,

Download date: 26 Apr. 2023 
Influence of CYP3A5 Genetic Polymorphism on Long-Term Renal Function in Chinese Kidney Transplant Recipients Using Limited Sampling Strategy and Abbreviated Area Under the Curve for Tacrolimus Monitoring

\author{
Chi Yuen Cheung, MD, PhD, FHKAM, FHKCP' ${ }^{\circledR}$, \\ Koon Ming Chan, FHKAM, FHKCP', Yuen Ting Wong, MRCP, MBBS', \\ Wai Leung Chak, FHKAM, FHKCP', Otto Bekers, PhD², \\ and Johannes P. van Hooff, MD, PhD $^{3}$
}

\begin{abstract}
Introduction: Although the association between CYP3A5 gene polymorphism and tacrolimus dosing requirements was well established, the impact on how CYP3A5 genotype affects the acute rejection and long-term renal function in patients who received kidney transplants and were treated with tacrolimus remained controversial. Design: Sixty-seven Chinese patients with kidney transplants receiving de novo tacrolimus-based immunosuppressive therapy with known CYP3A5 genotype were divided into 2 groups. Those with at least I CYP3A5*I allele were CYP3A5 expressers while homozygotes for the mutant allele CYP3A5*3 were nonexpressers. Instead of trough level, our center used abbreviated area under the curve for tacrolimus monitoring. Primary outcome was the long-term renal function between both groups while secondary outcomes included the weight-adjusted daily tacrolimus dose, graft survival, incidence of biopsy-proven acute rejection (BPAR), opportunistic infection, and cancer. Results: Thirty-five (52.2\%) patients were CYP3A5 expressers while 32 were nonexpressers. Mean daily tacrolimus dose in the CYP3A5 expressers and nonexpressers was $0.08(0.03)$ and $0.05(0.02) \mathrm{mg} / \mathrm{kg}$, respectively $(P<.01)$. Starting from I-month posttransplant, the renal function was comparable between both groups, which persisted up to I0-year. Ten patients experienced BPAR rejection and there was no significant difference in the rejection-free survival between both groups $(P=.87)$. There was also no significant difference in the death-censored graft survival between both groups $(P=.86)$. Finally, the incidence of opportunistic infection and posttransplant cancer was similar between them. Discussion: There was no significant difference in renal function, graft survival, and acute rejection between CYP3A5 expressers and nonexpressers.
\end{abstract}

\title{
Keywords
}

kidney transplant, pharmacogenetics, tacrolimus

\section{Introduction}

Tacrolimus is a calcineurin inhibitor that is widely used after kidney transplant. It has a narrow therapeutic index and demonstrates substantial interpatient and intrapatient variation in oral bioavailability. ${ }^{1}$ Tacrolimus is metabolized mainly by the cytochrome P450 3A4/5 (CYP3A4/5) system. Unlike CYP3A4 polymorphisms that rarely affects CYP3A4 expression, single nucleotide polymorphism (SNP) CYP3A5 6986G or *3 can lead to the absence of CYP3A5 expression. Individuals heterozygotes or homozygotes for the wild-type allele (CYP3A5*1) express CYP3A5 (expressers) while those homozygotes for the

\footnotetext{
' Renal Unit, Department of Medicine, Queen Elizabeth Hospital, Hong Kong

${ }^{2}$ Department of Clinical Chemistry, Central Diagnostic Laboratory, Maastricht University Medical Centre, Maastricht, the Netherlands

${ }^{3}$ Department of Internal Medicine, Maastricht University Medical Centre, Maastricht, the Netherlands
}

Corresponding Author:

Chi Yuen Cheung, Department of Medicine, Queen Elizabeth Hospital, 30 Gascoigne Road, Kowloon, Hong Kong.

Email: simoncycheung@gmail.com 
mutant allele CYP3A5*3 are nonexpressers. The CYP3A5 nonexpressers are present in $90 \%$ of the Caucasians, $53 \%$ of the Chinese, and $30 \%$ of the African American population. ${ }^{2-4}$

A meta-analysis of studies on patients who received kidney transplants and were treated with tacrolimus demonstrated that CYP3A5 expressers had an elevated risk of acute rejection and chronic nephrotoxicity compared with nonexpressers. ${ }^{5}$ Trough level $\left(C_{0}\right)$ was used for tacrolimus monitoring in these patients. However, there have been other studies showing that limited sampling strategy and abbreviated area under the curve (AUC) estimation has a better correlation with the full 12-hour AUC $\left(\mathrm{AUC}_{0-12}\right)$ when compared with trough level. ${ }^{6-8}$ Moreover, since most of the pharmacogenetic studies were conducted in predominantly Caucasian patients, a major drawback is the low percentage of CYP3A5 expressers in the analysis. In addition, it remains largely unknown whether the ethnic difference of CYP3A5 genotypes is related to the long-term graft outcomes. A recent retrospective study demonstrated that African American patients who received kidney transplants with CYP3A5*1 expression had an increased risk of delayed graft function and acute rejection. ${ }^{9}$ In view of the limited data in racially heterogeneous populations, we designed this study to compare the long-term renal outcome between CYP3A5 expressers and nonexpressers in the Chinese patients who received kidney transplants and were treated with tacrolimus using limited sampling strategy and abbreviated AUC for therapeutic drug titration.

\section{Methods}

\section{Design}

This was a retrospective cohort study approved by our Research Ethics Committee, IRB approval number: REC (KC/KE)-18-0105/ER-2. This study was carried out according to the Declaration of Helsinki.

\section{Setting}

The patients were recruited during follow-up in the transplant clinic in Queen Elizabeth Hospital, Hong Kong.

\section{Population}

Within the period between July 1, 1996, and June 30, 2005, 342 adult patients with end stage kidney disease received kidney transplant. All of them were Chinese. The commonest primary cause of kidney failure was glomerulonephritis $(55.5 \%)$. The mean age at transplant was $42.6(9.1)$. Ten $(2.9 \%)$ belonged to living-related transplant. Among these 342 patients, 168 patients received tacrolimus-based immunosuppressive therapy (118 de novo treatment vs 50 secondary treatment with tacrolimus).

\section{Sampling}

In a previous pharmacogenetic study conducted by our group, 103 of the 168 patients treated with tacrolimus consented for the genotyping assay for CYP3A $5 * 3 \mathrm{SNP}$ and subsequent study of the impact of this genotype on long-term renal outcome. The method of genomic analysis was described in detail in the study. ${ }^{4}$ Among these 103 patients, only those received de novo tacrolimus-based immunosuppressive therapy were recruited in this study. Patients who received de novo cyclosporine-based therapy after transplant and converted to tacrolimus-based therapy subsequently due to acute rejection or side effects of cyclosporine were excluded.

The starting dose of tacrolimus (Prograf, Astellas) was $0.3 \mathrm{mg} / \mathrm{kg} / \mathrm{d}$ given twice daily. A pharmacokinetic study involving Chinese patients who received kidney transplants demonstrated that tacrolimus trough level had a poor correlation with $\operatorname{AUC}_{0-12}\left(R^{2}=0.12 ; P=.17\right)$. Abbreviated sampling equations were then derived by multiple, stepwise regression analyses using $\mathrm{AUC}_{0-12}$ as the dependent variable and tacrolimus concentrations at different time points as the independent variables. Abbreviated AUC calculated by the 2-time point regression equation $16.2+\left(C_{2} \times 2.4\right)+\left(C_{4} \times 5.9\right), C_{2}$ : 2-hour postdose tacrolimus concentration and $C_{4}$ : 4-hour postdose tacrolimus concentration, gave an $R^{2}$ of $0.93 .^{6}$ Thus abbreviated AUC calculated from this equation was used for therapeutic drug monitoring (target AUC: 100 to $150 \mathrm{ng} \cdot \mathrm{h} / \mathrm{mL}$ in first 3 months posttransplant and 80 to $100 \mathrm{ng} \cdot \mathrm{h} / \mathrm{mL}$ afterward). ${ }^{6}$ The dosenormalized AUC (dnAUC) was the AUC divided by 24-hour dose on a milligram per kilogram basis.

Other immunosuppressive drugs in our study included steroids and azathioprine. Patients were given 1 dose of intravenous methylprednisolone $500 \mathrm{mg}$ on day 1 , followed by intravenous hydrocortisone $100 \mathrm{mg}$ every 6 hours. After 3 days, hydrocortisone was switched to oral prednisolone $30 \mathrm{mg} / \mathrm{d}$. The prednisolone dose was tailed down gradually $(2.5 \mathrm{mg}$ every 2 weeks after first month) and maintained at $5 \mathrm{mg} / \mathrm{d}$. Azathioprine was also administered $(1.5 \mathrm{mg} / \mathrm{kg} / \mathrm{d})$ since day 1 . All patients were given the choice of interleukin 2 receptor antagonist during induction therapy. Those who agreed would be given basiliximab (Simulect, Novartis) $20 \mathrm{mg} 2$ hours before transplant then 4 days after transplant. A 3-day course of pulse methylprednisolone $500 \mathrm{mg} / \mathrm{d}$ was the first-line therapy for acute rejection while antibody therapy was administered for steroid-resistant rejection. None of the patients included in this study was taking drugs that could interact with tacrolimus.

\section{Data Collection}

All patients' basic demographic and clinical parameters including recipient age, gender, body mass index, duration of dialysis, causes of end-stage kidney disease, living or deceased transplant, anastomotic time, cold ischemic time, donor age, human leukocyte antigen matching, and concomitant immunosuppressive drugs were extracted from medical record. Renal function was assessed by the estimated glomerular filtration rate (eGFR), which was calculated with the abbreviated modification of diet in renal disease formula. ${ }^{10}$ Biopsy-proven acute rejection (BPAR) was defined according to the revised Banff criteria and read by a single pathologist. ${ }^{11}$ Opportunistic 
infection was defined as an infection due to a microorganism/ virus that normally did not cause disease but became pathogenic when there was an impairment of the immune system. All diagnosed cancers were verified with histology and information such as radiological imaging and coded according to the 10th World Health Organization International Classification of Disease.

\section{Data Analysis}

The primary outcome was the eGFR compared between CYP3A5 expressers and nonexpressers. The secondary outcomes included the AUC, weight-adjusted daily tacrolimus dose $(\mathrm{mg} / \mathrm{kg})$ required to achieve the target AUC, graft survival, incidence of BPAR, opportunistic infection, and posttransplant cancer.

Statistical analysis was performed with SPSS v23 (IBM CorpArmonk). Categorical data were expressed as percentages and compared with chi-square or Fisher exact tests. Continuous data were expressed as mean (standard deviation) or median (range) and compared with $t$ test or Mann-Whitney $U$ test. Graft survival was calculated from the time of kidney transplant to the time of resumption of dialysis or patient death or December 31, 2017. Kaplan-Meier method and log-rank test were used to compare the survival between groups. A $P$ value $<.05$ was considered statistically significant.

\section{Results}

Sixty-seven patients who consented for this substudy and received de novo tacrolimus-based therapy were analyzed. All of them received the first kidney transplant. The frequency distribution of CYP3A $5 * 1 / * 1, \quad \mathrm{CYP} 3 \mathrm{~A} 5 * 1 / * 3$, and CYP3A $5 * 3 / * 3$ genotypes were $11.9 \%(\mathrm{n}=8), 40.3 \%(\mathrm{n}=$ $27)$, and $47.8 \%(\mathrm{n}=32)$, respectively. Thus $35(52.2 \%)$ patients were CYP3A5 expressers while 32 were nonexpressers. The basic demographic data and the transplant characteristics of our cohort were compared in Table 1. Although the cold ischemic time in the CYP3A5 expresser group was significantly longer than the CYP3A5 nonexpresser group, all patients in both groups have cold ischemic time less than 24 hours.

The starting dose of tacrolimus in both groups was $0.3 \mathrm{mg} /$ $\mathrm{kg} / \mathrm{d}$. From the first month onward, the patients in the CYP3A5 expresser group required a significantly higher dose of tacrolimus to maintain the target tacrolimus AUC. The mean daily tacrolimus maintenance dose in the CYP3A5 expressers and nonexpressers was $0.08(0.03)$ and $0.05(0.02) \mathrm{mg} / \mathrm{kg}$, respectively $(P<.01)$. The dnAUC in the CYP3A5 expressers and nonexpressers was 1258 (429) and 2803 (1536) $\mathrm{ng} \cdot \mathrm{h} / \mathrm{mL} / \mathrm{mg} /$ $\mathrm{kg}$, respectively $(P<.01)$.

At 1-month posttransplant, the eGFR was comparable between both groups, which persisted up to 10-year (Table 2). Totally, 13 patients had graft failure within the follow-up period (4 due to chronic rejection, 4 acute rejection, 4 recurrent glomerulonephritis, and 1 unknown cause). Among them, 7
Table I. Basic Demographic and Clinical Parameters Between CYP3A5 Expressers and Nonexpressers.

\begin{tabular}{|c|c|c|c|}
\hline & $\begin{array}{l}\text { CYP3A5 } \\
\text { expressers } \\
(n=35)\end{array}$ & $\begin{array}{c}\text { CYP3A5 } \\
\text { nonexpressers } \\
(\mathrm{n}=32)\end{array}$ & $\begin{array}{c}P \\
\text { value }\end{array}$ \\
\hline Age at transplant, years & $42.9(7.7)$ & $41.9(10.9)$ & .67 \\
\hline Male, n (\%) & $17(48.6)$ & $17(53.1)$ & .71 \\
\hline Body mass index, $\mathrm{kg} / \mathrm{m}^{2}$ & $21.6(2.3)$ & $22.7(4.3)$ & .22 \\
\hline Duration of dialysis, years & $5.4(3.9)$ & $3.9(2.7)$ & .20 \\
\hline Causes of ESKD, n (\%) & & & .79 \\
\hline Glomerulonephritis & $18(51.4)$ & $20(62.5)$ & \\
\hline Diabetes & $3(8.6)$ & $3(9.4)$ & \\
\hline Hypertension & $3(8.6)$ & $2(6.2)$ & \\
\hline Unknown/others & II (3I.4) & $7(21.9)$ & \\
\hline $\begin{array}{l}\text { Deceased/living transplant, } \\
\mathrm{n}(\%)\end{array}$ & $\begin{array}{c}34(97.1) / \\
\text { I (2.9) }\end{array}$ & $\begin{array}{c}31(96.9) / \\
\mathrm{I}(3.1)\end{array}$ & 1.00 \\
\hline Anastomotic time, minutes & $48.6(7.5)$ & $48.6(10.2)$ & .99 \\
\hline Cold ischemic time, hours & II.7 (7.4) & $7.0(4.3)$ & .02 \\
\hline Donor age, years & $45.4(11.6)$ & $46.2(16.8)$ & .89 \\
\hline HLA-AB mismatch & $2.5(1.2)$ & $2.0(1.3)$ & .19 \\
\hline HLA-DR mismatch & I.I (0.7) & $0.8(0.8)$ & .29 \\
\hline Use of IL-2 antagonist, $n$ (\%) & $13(37.1)$ & $13(40.6)$ & .77 \\
\hline Follow-up duration, months & $170(58-254)$ & $178(52-240)$ & .76 \\
\hline
\end{tabular}

Abbreviations: AUC, area under the curve; eGFR, estimated glomerular filtration rate; ESKD, end-stage kidney disease; HLA, human leukocyte antigen; IL, interleukin.

Table 2. Renal Function and Daily Tacrolimus Dose Between CYP3A5 Expressers and Nonexpressers.

\begin{tabular}{lccc}
\hline & $\begin{array}{c}\text { CYP3A5 } \\
\text { expressers } \\
(\mathrm{n}=35)\end{array}$ & $\begin{array}{c}\text { CYP3A5 } \\
\text { nonexpressers } \\
(\mathrm{n}=32)\end{array}$ & $\begin{array}{c}P \\
\text { value }\end{array}$ \\
\hline eGFR, mL/min/I.73m2 & & & \\
I-Month & $49(18)$ & $50(2 \mathrm{I})$ & .92 \\
6-Month & $51(17)$ & $52(18)$ & .79 \\
I-Year & $51(15)$ & $57(25)$ & .22 \\
5-Year & $57(20)$ & $56(22)$ & .99 \\
I0-Year & $62(24)$ & $54(21)$ & .18 \\
Tacrolimus AUC, ng.h/mL & & & \\
I-Month & $120(32)$ & $161(49)$ & $<.01$ \\
6-Month & $102(23)$ & $111(20)$ & .15 \\
I-Year & $98(19)$ & $98(22)$ & .88 \\
5-Year & $89(17)$ & $95(29)$ & .62 \\
Weight-adjusted daily & & & \\
tacrolimus dose, mg/kg & & & $<.01$ \\
I-Month & $0.18(0.06)$ & $0.13(0.05)$ & $<.01$ \\
6-Month & $0.12(0.05)$ & $0.07(0.03)$ & $<.01$ \\
I-Year & $0.11(0.06)$ & $0.05(0.02)$ & $<.01$ \\
5-Year & $0.08(0.03)$ & $0.05(0.02)$ & $<.01$ \\
\hline
\end{tabular}

Abbreviations: AUC, area under the curve; eGFR, estimated glomerular filtration rate.

were CYP3A5 expressers and 6 were nonexpressers. There was no significant difference in the death-censored graft survival between both groups $(P=.86)$.

In our cohort, 10 patients (5 in each group) experienced BPAR within the study period. Seven of them occurred within 
the first year of transplant; 4 (11.4\%) in the CYP3A5 expresser group and $3(9.4 \%)$ in the nonexpresser group. The overall 1 -year acute rejection rate was $10.4 \%$. Only 3 patients had acute rejection within the first month of transplant (1 with CYP 3 A $5 * 1 / * 3$ and 2 with CYP 3 A $5 * 3 / 3$ ). There was no significant difference in the acute rejection-free survival between both groups $(P=.87)$.

Nine $(25.7 \%)$ patients in the CYP3A5 expresser group and $11(34.3 \%)$ in the nonexpresser group had opportunistic infection. There was no significant difference between them $(P=$ .44). In addition, there was also no significant difference in the incidence of posttransplant cancer between both groups (6 in CYP3A5 expressers and 4 in nonexpressers, $P=.74$ ).

\section{Discussion}

The association between CYP3A5 gene polymorphism and required tacrolimus dose has been known for many years. ${ }^{4,12,13}$ CYP3A5 expressers display a lower dnAUC and require a significantly higher dose of tacrolimus in order to achieve the target therapeutic range compared to CYP3A5 nonexpressers. ${ }^{4}$ This difference can be explained by the CYP3A5 polymorphic expression and the corresponding enzymatic activity. CYP3A $5 * 3$ allele produces a cryptic splice site that results in an abnormal spliced messenger RNA (mRNA) with a premature stop codon and reduced enzymatic activity. By contrast, CYP3A5*1 allele produces a normal mRNA and codes for a functional enzyme that can increase the metabolism of tacrolimus and therefore higher doses are required. ${ }^{14}$

The data of CYP3A5 gene polymorphism on clinical outcome were limited and conflicting. MacPhee et al found that patients expressing CYP3A5 enzyme were more likely to have subtherapeutic levels of tacrolimus compared to the CYP3A5 nonexpressers within the first 2 weeks after transplant. The early subtherapeutic tacrolimus concentrations did not result in higher rates of acute rejection in CYP3A5 expressers. However, rejection occurred significantly earlier for individuals with a CYP3A $5 * 1$ allele compared to the nonexpressers (7 days vs 13 days, $P=.005) .{ }^{15}$ In a study of 103 patients with kidney transplants, Gervasini et al found that CYP3A5 polymorphism had no impact on rates of acute rejection, eGFR, or tacrolimus toxicity. ${ }^{13}$

Another study with 209 patients also failed to demonstrate any relationship between CYP3A5 genotype and renal function, rate of BPAR, delayed graft function, or biopsy-proven tacrolimus toxicity. ${ }^{16}$ A large observational study with 577 patients again failed to show any significant association between CYP3A5 polymorphism with BPAR, renal function, or graft survival. ${ }^{17}$ In a meta-analysis comprising 1246 patients, Terrazzino et al reported that the acute rejection rate was similar between CYP3A5 expressers and nonexpressers. ${ }^{18}$ A recently published meta-analysis (21 studies with 2185 patients) demonstrated a higher incidence of acute rejection and chronic nephrotoxicity in CYP3A5 expressers when compared to nonexpressers. ${ }^{5}$ In our study, there was no significant difference between CYP3A5 expressers and nonexpressers in renal function, graft survival, and acute rejection. The overall 1 -year acute graft rejection was $10.4 \%$, which was comparable with other studies. ${ }^{19,20}$ One reason why CYP3A5 expressers and nonexpressers have similar episodes of acute rejection could be related to the higher starting dose of tacrolimus in our study. In our center, the initial tacrolimus dose was $0.3 \mathrm{mg} / \mathrm{kg} / \mathrm{d}$, which was much higher than the dose started in other centers $(0.1-0.2 \mathrm{mg} / \mathrm{kg} / \mathrm{d}){ }^{9,20-23}$ As a result, the mean tacrolimus AUC had already reached the target range at 1-month posttransplant in the CYP3A5 expressers. The mean tacrolimus AUC was significantly higher in the CYP3A5 nonexpressers at 1-month (161 vs $120 \mathrm{ng} \cdot \mathrm{h} / \mathrm{mL}, P<.01$ ), which required dose reduction.

In agreement with most of the studies described above, we could not demonstrate any significant difference in long-term renal function (up to 10 years) and graft survival between CYP3A5 expressers and nonexpressers. It is generally believed that the differences in pharmacokinetics could hardly translate into differences in clinical outcomes. One reason is that patients who receive kidney transplants usually have intensive therapeutic drug monitoring with titration of tacrolimus in the first few weeks after transplant. This together with other nongenetic factors such as doses of steroid, serum albumin levels, and drug interactions could mask the effect of genetic polymorphisms. ${ }^{13}$

A major drawback of our study was the retrospective design. Since the median duration between kidney transplant and pharmacogenetic assays in our cohort was 36 (5-104) months, this could result in an overrepresentation of patients with better outcome (selection bias). In addition, our cohort size was small, and there might be insufficient power to detect the difference of clinical outcomes between both groups. Since our cohort was all Chinese patients, there was a much higher percentage of CYP3A5*1 carriers $(52.2 \%)$ when compared to the studies mainly comprising Caucasian patients. ${ }^{21,24}$ Moreover, the median follow-up of our cohort was more than 10 years, which should be long enough to study the long-term clinical outcome of different CYP3A5 genotype.

\section{Conclusion}

The findings in our cohort show that CYP3A5 expressers had a lower dnAUC and required a higher dose of tacrolimus to achieve the target therapeutic range compared to nonexpressers. There was no significant difference in long-term renal function, graft survival, and acute rejection between CYP3A5 expressers and nonexpressers when abbreviated AUC was used for therapeutic drug monitoring.

\section{Declaration of Conflicting Interests}

The author(s) declared no potential conflicts of interest with respect to the research, authorship, and/or publication of this article

\section{Funding}

The author(s) received no financial support for the research, authorship, and/or publication of this article. 


\section{ORCID iD}

Chi Yuen Cheung (D) https://orcid.org/0000-0001-9940-2568

\section{References}

1. Staatz CE, Tett SE. Clinical pharmacokinetics and pharmacodynamics of tacrolimus in solid organ transplantation. Clin Pharmacokinet. 2004;43(10):623-653.

2. Xie HG, Wood AJ, Kim RB, Stein CM, Wilkinson GR. Genetic variability in CYP3A5 and its possible consequences. Pharmacogenomics. 2004;5(3):243-272.

3. van Schaik RH, van der Heiden IP, van den Anker JN, Lindemans J. CYP3A5 variant allele frequencies in Dutch Caucasians. Clin Chem. 2002;48(10):1668-1671.

4. Cheung CY, Op den Buijsch RA, Wong KM, et al. Influence of different allelic variants of the CYP3A and $\mathrm{ABCB} 1$ genes on the tacrolimus pharmacokinetic profile of Chinese renal transplant recipients. Pharmacogenomics. 2006;7(4):563-574.

5. Rojas L, Neumann I, Herrero MJ, et al. Effect of CYP3A5*3 on kidney transplant recipients treated with tacrolimus: a systematic review and meta-analysis of observational studies. Pharmacogenomics J. 2015;15(1):38-48. doi:10.1038/tpj.2014.38

6. Wong KM, Shek CC, Chau KF, Li CS. Abbreviated tacrolimus area-under-the-curve monitoring for renal transplant recipients. Am J Kidney Dis. 2000;35(4):660-666.

7. Mathew BS, Fleming DH, Jeyaseelan V, et al. A limited sampling strategy for tacrolimus in renal transplant patients. $\mathrm{Br} J$ Clin Pharmacol. 2008;66(4):467-472. doi:10.1111/j.1365-2125. 2008.03251.x

8. Armendáriz Y, Pou L, Cantarell C, Lopez R, Perelló M, Capdevila $\mathrm{L}$. Evaluation of a limited sampling strategy to estimate area under the curve of tacrolimus in adult renal transplant patients. Ther Drug Monit. 2005;27(4):431-434.

9. Asempa TE, Rebellato LM, Hudson S, Briley K, Maldonado AQ. Impact of CYP3A5 genomic variances on clinical outcomes among African American kidney transplant recipients. Clin Transplant. 2018;32(1). doi:10.1111/ctr.13162

10. Levey AS, Coresh J, Greene T, et al. Using standardized serum creatinine values in the modification of diet in renal disease study equation for estimating glomerular filtration rate. Ann Intern Med. 2006;145(4):247-254.

11. Loupy A, Haas M, Solez K, et al. The Banff 2015 Kidney Meeting Report: Current Challenges in Rejection Classification and Prospects for Adopting Molecular Pathology. Am J Transplant. 2017;17(1):28-41. doi:10.1111/ajt.14107

12. Macphee IA, Fredericks S, Mohamed M, et al. Tacrolimus pharmacogenetics: the CYP3A $5 * 1$ allele predicts low dosenormalized tacrolimus blood concentrations in whites and South Asians. Transplantation. 2005;79(4):499-502.

13. Gervasini G, Garcia M, Macias RM, Cubero JJ, Caravaca F, Benitez J. Impact of genetic polymorphisms on tacrolimus pharmacokinetics and the clinical outcome of renal transplantation.
Transpl Int. 2012;25(4):471-480. doi:10.1111/j.1432-2277. 2012.01446. $\mathrm{x}$

14. Staatz CE, Goodman LK, Tett SE. Effect of CYP3A and ABCB1 single nucleotide polymorphisms on the pharmacokinetics and pharmacodynamics of calcineurin inhibitors: Part II. Clin Pharmacokinet. 2010;49(4):207-21. doi:10.2165/11317550-00000000000000

15. MacPhee IA, Fredericks S, Tai T, et al. The influence of pharmacogenetics on the time to achieve target tacrolimus concentrations after kidney transplantation. Am J Transplant. 2004; 4(6):914-919.

16. Glowacki F, Lionet A, Buob D, et al. CYP3A5 and ABCB1 polymorphisms in donor and recipient: impact on tacrolimus dose requirements and clinical outcome after renal transplantation. Nephrol Dial Transplant. 2011;26(9):3046-3050. doi:10.1093/ ndt/gft253

17. Flahault A, Anglicheau D, Loriot MA, Thervet E, Pallet N. Clinical impact of the CYP3A5 6986A $>\mathrm{G}$ allelic variant on kidney transplantation outcomes. Pharmacogenomics. 2017; 18(2):165-173. doi:10.2217/pgs-2016-0146

18. Terrazzino S, Quaglia M, Stratta P, Canonico PL, Genazzani AA. The effect of CYP3A5 6986A $>\mathrm{G}$ and ABCB1 3435C $>$ T on tacrolimus dose-adjusted trough levels and acute rejection rates in renal transplant patients: a systematic review and meta-analysis. Pharmacogenet Genomics. 2012;22(8):642-645. doi:10.1097/FPC.0b013e3283557c74

19. Laskow DA, Vincenti F, Neylan JF, Mendez R, Matas AJ. An open-label, concentration-ranging trial of FK506 in primary kidney transplantation: a report of the United States Multicenter FK506 Kidney Transplant Group. Transplantation. 1996;62(7): 900-905.

20. Ekberg H, Tedesco-Silva H, Demirbas A, et al. Reduced exposure to calcineurin inhibitors in renal transplantation. $N$ Engl J Med. 2007;357(25):2562-2575.

21. Quteineh L, Verstuyft C, Furlan V, et al. Influence of CYP3A5 genetic polymorphism on tacrolimus daily dose requirements and acute rejection in renal graft recipients. Basic Clin Pharmacol Toxicol. 2008;103(6):546-552. doi:10.1111/j.1742-7843. 2008.00327.x

22. Yang HC. Tailoring tacrolimus-based immunotherapy in renal transplantation. Nephrol Dial Transplant. 2003;18(suppl 1): 16-20.

23. Ahsan N, Johnson C, Gonwa T, et al. Randomized trial of tacrolimus plus mycophenolate mofetil or azathioprine versus cyclosporine oral solution (modified) plus mycophenolate mofetil after cadaveric kidney transplantation: results at 2 years. Transplantation. 2001;72(2):245-250.

24. Hesselink DA, van Schaik RH, van Agteren M, et al. CYP3A5 genotype is not associated with a higher risk of acute rejection in tacrolimus-treated renal transplant recipients. Pharmacogenet Genomics. 2008;18(4):339-344. doi:10.1097/FPC.0b013e 3282f75f88 